УДК 33.316 .334 .37

\title{
РЫНОЧНАЯ ЭКОНОМИКА: ГЕНЕЗИС И ПРИНЦИПЫ СТАНОВЛЕНИЯ И РАЗВИТИЯ
}

\author{
В.А. КЛИМЕНКО, \\ д-р соц. наук, профессор, \\ консультант Исполнительного комитета СНГ
}

\begin{abstract}
Аннотация
Рассматриваются генезис и принципы становления и развития рыночной экономики, различные типь экономического порядка (экономических систем), основныле виды и методы регулирования государством экономических прочессов.

Ключевые слова: рыночная экономика, развитие рыночной экономики, становление рыночной экономики, методы государственного регулирования.

Abstract

The genesis and principles of formation and development of the market economy, various types of economic order (economic systems), basic types and methods of state regulation of economic processes are viewed in the article.

Key words: market economy development of market economy, emergence of market economy, methods of state regulation.

\section{ВВЕДЕНИЕ}

Экономика страны является основой развития любого государства, гарантией его независимости, условием стабильности и эффективности жизнедеятельности общества. Экономика - это особая сфера, которая связана с производством, распределением и потреблением товаров, благ и услуг. Она обеспечивает материальную жизнеспособность общества, создает условия развития отдельного человека и социума в целом. Уровень развития экономики определяет уровень и качество жизни народа, течение политических, социальных и социокультурных процессов.

В экономике, как и в других областях человеческой жизни: политике, культуре, социальной сфере, существуют свои законы, «правила и игры», которые обеспечивают функционирование большинства экономических субъектов и предотвращают хаос в экономических процессах. Они в совокупности определяют организационную структуру экономики страны и сам ход экономических процессов.
\end{abstract}

\section{РЕЗУЛЬТАТЫ И ИХ ОБСУЖДЕНИЕ}

В научной литературе под экономическими правилами подразумеваются такие понятия как «экономический порядок», «экономическая система», «экономическое законодательство», которые не имеют единой научной трактовки и их можно определить как понятия-синонимы. Следует подчеркнуть, что любой экономический порядок (экономическая система) предопределяется условиями культурной, политической и социальной жизни общества. В тоже время, определенный экономический порядок формирует общественно-политическую систему государства и служит высшим целям общества.

В реальной жизни каждая экономическая система того или иного государства характеризуется многими свойствами и признаками. Однако существует два основных критерия, которые в значительной степени определяют экономическую модель обще- 
ства. Таковыми являются: а) виды и способы координации экономической деятельности; б) отношение к собственности на средства производства.

Смысл любой экономики состоит в том, чтобы максимально удовлетворить, использовав все имеющиеся средства, потребности членов общества. Поэтому в любой экономической системе, независимо от степени ее развития встают три проблемы: какие товары и какого качества необходимо производить - проблема выбора (проблема селекции); какие производственные факторы и ресурсы необходимо использовать и в каких количествах - проблема использования (аллокационная проблема); как распределить произведенный товар между членами общества - проблема распределения (проблема дистрибуции) [1, с. 2-3].

В плановой социалистической экономике эти три проблемы решаются централизованно, через какую-либо государственную инстанцию. В рыночной экономике это осуществляется децентрализовано через рыночный механизм. Из этого не следует, что в рыночной экономике отсутствует планирование. Экономическая деятельность любой фирмы, организации в рыночной экономике опирается на программы и планы. Отличие между двумя экономическими моделями состоит в форме координации экономической деятельностью. В плановой социалистической экономике доминировала централизованная система управления экономикой, в рыночной, как было сказано выше, координация планов осуществляется децентрализовано через рыночный механизм.

Вторым определяющим фактором отнесения экономической системы к той или иной экономической модели, является отношение к средствам производства. Право собственности является основой всей системы экономических отношений, ибо формы собственности и формы хозяйствования определяют и обеспечивают главный двигатель развития - личную заинтересованность и мотивацию. Собственность может находиться либо в частных руках (частная собственность), либо в общественных (общественная, государственная собственность). В соответствии с этим различают две формы общественного строя - капитализм и социализм.

На основе сочетания обоих структурных признаков, а именно: формы собственности (частная и общественная (государственная) и формы координации (централизованная и децентрализованная) можно вычленить четыре теоретических типа общественного порядка: капиталистическая рыночная экономика, социалистическая рыночная экономика, капиталистическая централизованная экономика, социалистическая централизованная экономика. Однако в реальности жизнеспособны две основные экономические модели: капиталистическая рыночная экономика и социалистическая централизованная экономика. Две другие экономические модели (капиталистическая централизованная экономика и социалистическая рыночная экономика), исходя из своей «конструкции» рано или поздно разрушаются вследствие возникновения внутренних противоречий. Для капитализма, как известно, характерно доминирование частной собственности на средства производства, в тоже время «централизованная экономика» означает, что управление экономическими субъектами (что производить, сколько и куда реализовывать) осуществляется центральным государственным органом, то есть государством. Все это приводит к внутреннему конфликту между двумя составляющими данной модели. Не жизнеспособна и социалистическая рыночная экономика («рыночный социализм»), ибо государственные предприятия и даже предприятия, основанные на коллективной собственности в условиях рыночной конкуренции не выживают, так как в большинстве полученную прибыль направляют не на развитие производства, а на потребление.

Централизованная координация и общественная (государственная) собственность представляют собой единое целое в той же степени, что и рыночный механизм и частная собственность. Следует подчеркнуть, что в современных условиях все реальные экономические системы имеют смешанные формы, ибо даже в любой рыночной эконо- 
мике наблюдаются в той или иной степени элементы централизованной экономики и государственной собственности.

Рыночная экономика - это экономика, в рамках которой большая часть экономической деятельности по производству, распределению товаров (услуг) и их обмену осуществляется частными лицами или корпоративными организациями, которые подчиняются диктату спроса и предложения. При этом государственное вмешательство во все сферы экономики сводится к минимуму. Именно так выделяет экономический аспект понятия «рынок» веберовская социология. Сам же М. Вебер считал развитие рыночной экономики основой роста индустриального капитализма, который является классической формой капитализма, наиболее рельефно проявившегося в XIX веке в Великобритании и США. В его работе «Протестантская этика и дух капитализма» (1905 г.) обосновывалась идея, что светская культура капиталистического общества берет свое начало в аскетизме протестантской реформации. Протестантизм противопоставлял автономию и независимость индивида зависимости от церкви и духовенства. Индивидуальная вера в Христа как спасителя человечества от греха является основным элементом протестантской доктрины. Только самоконтроль, кропотливый труд, служение общине способны привести к собственному спасению. Поэтому протестантизм обусловил значительную часть культурного содержания раннего капитализма - индивидуализм, достижительную мотивацию, враждебность к унаследованному богатству и роскоши, легитимацию предпринимательского призвания, неприятие магии и суеверия, преданность организации и расчету в личной и общественной жизни [2, с. 247].

Следует подчеркнуть, что протестантизм стал элементом рационализации западного общества, что нашло отражение в теории рационального выбора. Суть ее состоит в том, что социальным деятелям свойственно стремление к достижению определенных целей. Однако, стремясь к цели, действуя рационально, индивиды осуществляют выбор из ряда альтернатив оптимальным образом, то есть максимизируют выгоды, а затраты сокращают до минимума. Таким образом, в соответствии со своими предпочтениями, деятели выбирают действия, которые приносят наилучший результат. Стремление индивида к получению личной выгоды при капитализме проявляется в человеческом характере в наибольшей степени. «Капитализм, - подчеркивал М. Вебер, - может быть идентичным обузданию этого иррационального стремления, во всяком случае, его рациональному регламентированию. Капитализм, безусловно, тождественен стремлению к наживе в рамках непрерывно действующего рационального капиталистического предприятия, к непрерывно возрождающейся прибыли, к рентабельности» [3, с. 48].

Зарождение рыночных отношений берет свое начало с середины XVII столетия с распространения такого направления в философии как классический либерализм, который подвергал критике на политическом уровне господствующий в то время в Европе абсолютизм, а на экономическом уровне пропагандировал идею экономической свободы и рыночной координации (рыночного механизма).

Либерализм (от лат. Liberalis - касающийся свободы, присущий свободному человеку) - образ мышления и деятельности, для которого характерна независимость по отношению к традициям, привычкам, догмам, стремление и способность к активному самоопределению в мире. В соответствии с этим в экономической области либерализм требует отмены регламентаций и ограничений со стороны государственной власти, простора для частной инициативы, создания максимально свободных условий развертывания частного предпринимательства. Сформированные в XIX веке в трудах И. Бентама (17481832 гг.), Дж. С. Милля (1806-1873 гг.), Г. Спенсера (1820-1903 гг.) принципы либерализма получили свое развитие в новом течении - неолиберализме - доктрине, сохраняющей верность в экономической области принципам свободной конкуренции, частного предпринимательства. Новые принципы либерализма в 20-ом столетии воплощены, прежде всего, в концепциях К. Р. Поппера (1902-1992 гг.), Ф. Хайека (1899-1992 гг.) и 
других ученых, для которых в теоретико-методологическом плане также характерны такие черты, как индивидуализм и рационализм.

В экономической области одним из первых теоретически принципы классического либерализма, в основе которых лежит экономическая свобода индивидов, сформулировал А. Смит (1723-1790 гг.): «Естественное состояние каждого человека - улучшить свое положение, если ему обеспечена возможность свободно и беспрепятственно проявлять себя, представляет собой столь лучшее начало, что одно оно не только способно без всякого содействия со стороны довести общество до богатства и процветания, но и преодолеть сотни досадных препятствий, которыми безумие человеческих законов так часто затрудняет его деятельность...» [4, с. 393]. Поэтому А. Смит выступал против различных ограничений со стороны государства, которые могут сковывать личную инициативу индивидов и препятствовать достижению им своих целей. И хотя, по мнению А. Смита, в основе экономической деятельности индивидов лежат эгоистические интересы: стремление к успеху, к преумножению капитала, однако они оправданы, если не наносят вреда конкурентам. Исходя из этого А. Смит предлагает отменить правительственную регламентацию деятельности предприятий промышленности и внутренней торговли, выступает за свободную торговлю землей, свободную миграцию рабочей силы [5, с. 43].

Экономическая теория А. Смита, которого считают основателем учения о новой системе хозяйства, нашла отражение в период зарождения капиталистических отношений, когда шел процесс накопления капиталов в процессе свободной рыночной конкуренции между товаропроизводителями. В это время в философии доминировала концепция «естественного права», согласно которой человек, как разумное существо, сам познает свои собственные интересы и для их осуществления имеет право на свободу. И согласно концепции «естественного права» в обязанности государства входит выполнение только трех функций: ограждать общество от насилий и вторжения других независимых обществ; ограждать по мере возможности каждого члена общества от несправедливости и угнетения со стороны других его членов; создавать и содержать определенные общественные сооружения и учреждения, создание и содержание которых не может быть в интересах отдельных лиц или небольших групп, потому что прибыль от них никогда не сможет оплатить издержки отдельному лицу или небольшой группе, хотя и сможет часто с излишком оплатить их большому обществу [6, с. 498]. Таким образом, для экономики на стадии раннего зарождения капитализма свойственно было невмешательство государства в экономическую деятельность.

Для такого типа экономической организации общества, как капитализм, в его «чистой» форме характерно следующее 1) частная собственность на экономические средства производства (то есть капитал) и контроль над ними; 2) направленность экономической деятельности на получение прибыли; 3) наличие рынка, регулирующего эту деятельность; 4) присвоение собственниками капитала прибыли, подлежащей налогообложению со стороны государства; 5) труд рабочих в качестве свободных социальных деятелей [7, с. 279]. Следует подчеркнуть, что исторически капитализм развивался, определяя особенности всей экономической жизни европейских обществ, идя рука об руку с индустриализацией, однако, некоторые его черты обнаруживаются в практике торговли в доиндустриальный период и даже в эпоху средневековья. В Англии хорошо развитая система капиталистического сельского хозяйства появилась за полтора столетия до начала индустриализации.

Капитализм в индустриализованных обществах проявлялся в различных формах. Наиболее чистой, классической формой капитализма, как отмечалось выше, считается ранний индустриальный капитализм XIX века в Англии и Соединенных Штатах. В то время экономическая деятельность осуществлялась множеством небольших капиталистических фирм, находившихся в собственности индивидов или семейств, непосред- 
ственно ими управлявших. Экономическая деятельность регулировалась такой системой рынков, при которой господствовали простая конкуренция между производителями товаров и услуг и простой спрос со стороны потребителей. Рынок труда влиял на определение величины заработной платы и распределение рабочих мест между работодателями осуществлялось под воздействием тех же сил спроса и предложения. Экономика на данной стадии капитализма функционировала на основе принципа невмешательства (laissez-faire), то есть государство находилось в стороне от экономической деятельности, предоставляя ее регулирование рынку. Это в конечном итоге приводило к нестабильности и анархии в экономике.

Происшедшая в начале XIX века промышленная революция привела к новому этапу развития капитализма - индустриальному капитализму, что потребовало нового осмысления всей системы капиталистических отношений. Преемниками экономических взглядов А. Смита в последующие периоды развития капиталистической системы стали Д. Риккардо (1772-1823 гг.), Дж. Стюарт (1806-1873 гг.), Ж. Б. Сэй (17671832 гг.) и др. Развитие капитализма в XIX веке способствовало появлению крупной промышленности и крупного землевладения. Мелкие производители, ремесленники и торговцы не выдерживают конкуренции со стороны крупного промышленного и сельскохозяйственного производства. В результате развития мелких товарных производителей происходит концентрация собственности на средства производства. Это ведет к углублению социального неравенства. Государство вынуждено было вмешиваться в хозяйственную жизнь, стремясь регулировать экономические и социальные процессы.

B XIX веке в европейских странах, в Японии правительства используют такие методы регулирования экономических процессов, как субсидирование частных предпринимателей, кредитование определенных производств, создание государственных предприятий. Государство регулирует рынки труда и продукции не только экономическими, но и политическими средствами, устанавливая протекционистские тарифы, предоставляя монопольные права на производство определенных товаров или на торговлю в определенных районах. Уже к середине XIX века во многих европейских странах действовали законодательства в области ограничения рабочего дня, были введены ограничения на женский и детский труд, появляется система принудительного страхования от болезни, несчастных случаев, от инвалидности и старости. К концу XIX века - начала $\mathrm{XX}$ века контроль со стороны государства над экономической жизнью считался необходимым условием укрепления государственной власти, поддержания нормального уровня доходов государства и сохранения социального порядка.

В XX веке большинство капиталистических стран отошли от ранней классической модели. Стало очевидным, что свободный рынок не может быть универсальным средством регулирования экономики. Какими бы универсальными не были законы рынка, сам рынок является всего лишь механизмом, который приводит в движение всю систему капиталистического хозяйства. Когда происходит сбой в рыночном механизме, тогда необходимо вмешательство государства.

Более поздние формы «монополистического» капитализма, типичные для середины XX века, характеризовались экономической концентрацией и господством на рынке небольшого числа крупных фирм взамен конкуренции между многочисленными мелкими фирмами. При таких условиях обычной практикой для многих фирм было заключение соглашений об ограничении конкуренции и таком манипулировании рынками, которое вело бы к повышению прибыльности и стабильности. Более концентрированной стала также и собственность на капитал. Распределение акционерной формы собственности в начале XX века привело к рассредоточению собственности среди большого числа владельцев акций и упадку семейных фирм. Вследствие этого ослабилось традиционное единство собственности и управления, и контроль за повседневной деятельностью фирм стал переходить к профессиональным менеджерам. Последние 
стали определять также и более широкую политику компании в тех случаях, когда индивидуальные или семейные держатели акций сами по себе или в союзе с другими владельцами капитала не имели такой его доли, которая была бы достаточна для контроля над менеджментом. Однако, в последние сорок лет 20-го столетия в торговле наблюдался относительный упадок частного акционирования и увеличение доли собственности институциональной по мере вложения промежуточными финансовыми институтами (банками, страховыми компаниями, пенсионными фондами) значительных средств в акции компаний.

Экономическая роль государства становилась все более весомой даже в тех областях, где прежде применялись принципы невмешательства. На протяжении большей части XX века правительства стремились к достижению экономической стабильности и защите интересов местного капитала и труда. С этой целью государство использовало свое влияние в качестве покупателя товаров и услуг, а также систему государственных капиталовложений и субсидий. В большинстве европейских стран отстаивание национальных интересов проявлялось через развитие государственной собственности на часть промышленности, через регулирование частных инвестиций и процесса создания компаний путем выкупа предприятий, посредством контроля над уровнями заработной платы и цен. В современных условиях чаще всего наблюдаются следующие виды вмешательства регулирования государства в экономику: нормативное (правовое) и финансовое [8, с. 63].

Нормативное государственное регулирование направлено на обеспечение эффективной и справедливой работы рынков. Часто регулирование связано также с социальными ценностями государства (например, бесплатным медицинским обслуживанием, бесплатным образованием и др.). Финансовое государственное регулирование предлагает различного рода субсидии (или налоги), как средство воздействия на цены определенных видов продукции или доходы определенных категорий граждан. При этом ценовые субсидии могут быть частичными (например, низкая плата за обучение в государственных вузах, частичная оплата медобслуживания), либо полными (бесплатная система здравоохранения, бесплатное общее и другие виды образования). Говоря о степени вмешательства государства в экономические процессы, в целом можно сказать, что государственное вмешательство в рыночной экономике уместно в двух случаях: когда данный рынок неэффективен или когда вмешательство государства может привести к более эффективному результату, чем свободный рынок.

Таким образом, в современных условиях рыночных механизмов в «чистом» виде нет ни в одной стране капитализма, так как такого рода «чистые» механизмы ведут к острейшим диспропорциям и противоречиям в экономике, а, следовательно, к неразрешимым негативным последствиям в социальной сфере. Вмешательство государства в той или иной степени продолжает существовать во всех странах. Какими бы эффективными не были рыночные механизмы регулирования экономики, государство определяет национальную экономическую стратегию на основе социальных и политических целей.

Каковы же основные принципы рыночной экономики? Таковыми можно выделить следующие: свобода производства и потребления; эффективность экономической деятельности, получения дохода (прибыли); регулирование деятельности хозяйствующих субъектов самим рынком. Основополагающим принципом рыночной экономики является стремление к свободной экономической активности (свобода диспозиции экономических субъектов), что выражается в свободе производства и потребления.

Свобода производства означает: владение средствами производства; возможность создать предприятие; приобрести необходимые средства, привлечь по своему усмотрению рабочую силу и выпускать то, что желаешь производить. Свобода потребления означает свободу использования полученных доходов (прибыли). Свобода, как основной принцип функционирования рыночной экономики, представляет собой всеобъемлющее понятие. Это - свобода выбора профессии и рабочего места, свобода выбора по- 
требляемого товара, свобода предпринимательства, свобода распоряжения частным имуществом, включая средства производства и т.д.

Вторым, не менее важным, является принцип эффективности экономической деятельности, что выражается в том, что товар (услуга) находит своего потребителя на рынке и приносит доход. Именно потребители своими решениями (покупками) определяют эффективность той или иной экономической деятельности. Именно потребители в рыночной экономике определяют, что, как, когда и сколько производить. И в этом состоит одно из главных отличий рыночной экономики от плановой централизованной экономики.

Третий принцип заключается в том, что главным элементом мотивации для предприятия или предпринимателя в рыночной экономике является прибыль. Прибыль, как известно, представляет собой разницу между доходами и издержками производства. Поэтому любое предприятие стремится к достижению максимально высоких доходов в результате сбыта большого количества товаров по высоким ценам и к максимальному снижению издержек. Любое предприятие стремится к получению максимальной прибыли при господствующем положении на рынке. Господствующее положение на рынке не могут иметь сразу несколько предприятий, захвативших львиную долю рынка. Стараясь избежать конкурентной борьбы за потребителя, производители часто заключают соглашение с фирмами сбыта или со своими конкурентами. Созданные монопольные группы пытаются оказывать влияние на свободное ценообразование, что несовместимо с рыночной экономикой. В этом случае важная роль принадлежит государству, которое должно обеспечить функционирование конкурентной среды (равных условий для всех производителей) - основы рыночно-хозяйственных отношений.

И четвертый принцип рыночной экономики состоит в том, что координационным инструментом деятельности экономических субъектов выступает собственно рынок, который регулирует спрос и предложение товаров с помощью механизма цен. Именно рынок определяет в конечном итоге, «Что?», «Как?» и «Для кого?» производится товар.

Действие рыночного механизма в целом может быть представлено следующим образом. Вначале решение, что производить, принимают предприятия, а впоследствии, сами потребители определяют, что покупать. Это означает суверенитет потребителя, который своим решением определяет вид и объем производимых товаров, то есть определяет направление производства. В результате этого товар, который никому не нужен, не продается. Товар, который стоит дороже, при аналогичном качестве, также не продается. Производители, игнорирующие сигналы рынка, в конечном итоге, подвергаются банкротству. Выигрывают те производители, которые выпускают качественную (при этом, более дешевую) и пользующуюся спросом продукцию.

Исходя из собственных интересов (достижение прибыли) предприятия выбирают наиболее благоприятную по издержкам комбинацию производственных факторов. На рынках производственных факторов принимаются решения о том, каким способом будут изготовлены те или иные товары. Товары покупает тот, кто получает доходы. В свою очередь доходы получают лишь те, кто обеспечивает эффективность труда и представляет иные производственные средства, пользующиеся спросом, причем, чем ниже предложения, тем выше доход и тем больше растет спрос. Следовательно, ситуация на факторных рынках определяет, кто получает товар, какой товар и в каких количествах, то есть для кого, собственно, производится товар. При этом, следует отметить, что все рынки (в экономическом цикле) тесно переплетаются. Управление экономическими процессами, в конечном итоге, осуществляется совместно рынками в тесной взаимосвязи. Таким образом, производители и потребители, в первую очередь, своим предложением и спросом выдают информацию о своих намерениях и условиях обмена. Они одновременно реагируют на результат рыночной деятельности. Экономические процессы приводятся в действие двигателем эгоистических стремлений. Но в тоже 
время, в результате конкуренции с другими производителями достигается ситуация, когда прибыль одного из производителей не возрастает до необъятных размеров, а требования потребителей удовлетворяются в товарах необходимого качества и цены.

\section{ВЫВОДЫ}

Рыночная экономика не является экономическим порядком со строго установленными и неизменными правилами. Она может рассматриваться всего лишь как постоянно развивающийся процесс. В каждый период своего развития рыночная экономика проявляется в своих конкретных, специфических формах. Эта специфичность организационных форм рыночной экономики зависит от мировоззрения общества, миропонимания людей, трактовки ими места и роли человека в обществе и государстве, отношения человека к обществу и государству, от взаимодействия общества и государства и т.д.

\section{ЛИТЕРАТУРА}

1. Вилке Ф. Предприятие в рыночной экономике. - Шверте, 1994.

2. Аберкромби Н., Хилл С., Тернер Б. Социологический словарь. // Пер. с англ.; под ред. С.А. Ерофеева. - Казань: Изд. Казан. ун-та, 1997.

3. Вебер М. Избранные произведения. - М.: Прогресс, 1990.

4. Смит А. Исследование о природе и причинах богатства народов. - М.: Изд. Экономическая лит, 1962.

5. Тарасов В. С. Государство и экономическое развитие общества. - Минск.: Беларускі кнігазбор, 1999.

6. Смит А. Исследование о природе и причинах богатства народов. - М.: Изд-во Эконом. лит., 1962.

7. Аберкромби Н., Хилл С., Тернер Б. Социологический словарь - Казань: Изд-во Казанского университета, 1997.

8. Рынок труда и социальная политика в Центральной и Восточной Европе. Переходный период и дальнейшее развитие. // пер. с англ. - М.: ИКЦ «ДИС», 1997.

Статья поступила в редакичию 29 декабря 2015 года. 